\title{
Amorphous Urate Crystals Measurement
}

National Cancer Institute

\section{Source}

National Cancer Institute. Amorphous Urate Crystals Measurement. NCI Thesaurus.

Code C92244.

The determination of the amount of amorphous urate crystals present in a sample. 